There are hundreds or even thousands of chess studies in psychology and cognitive science, but it is pointed out that a Shogi study is virtually non-existent and that there are only a few Go studies He described recent cognitive scientific studies of the game of Go, including his own research Moreover, he mentioned what contribution Yoshikawa's and his own work could have on Wolf's Tsume-go program He concluded his lecture by pondering on what remains to be done

\title{
Reference
}

Koyama, K and Lay, T W (1994) An Optımal Mastermınd Strategy Journal of Recreatıonal Mathematıcs, Vol 25, No 4, pp 251-256

\section{ARTICLES PUBLISHED ELSEWHERE}

\section{B $^{\star}$ PROBABILITY BASED SEARCH ${ }^{1}$}

\author{
HJ Berliner and Chr McConnell \\ Pittsburgh, USA
}

Artıficial Intelligence 86 (1996), pp 97-156

We reproduce the abstract

"We describe a search algorithm for two-player games that relies on selectivity rather than brute-force to achieve success The key ideas behind the algorithm are

(1) stopping when one alternative is clearly better than all the others, and

(2) focusing the search on the place where the most progress can likely be made toward stopping

Critical to this process is identifying uncertainty about the ultımate value of any move The lower bound on uncertainty is the best estımate of the real value of a move The upper bound is its optimistic value, based on some measure of unexplored potential This provides an I-have-optımism-that-needs-to-be-investigated attitude that is an excellent guiding force Uncertainty is represented by probability distrıbutions The search develops those parts of the tree where moving existing bounds would be most likely to succeed and would make the most progress toward termınatıng the search Termınation is achieved when the established real value of the best move is so good that the likelihood of this being achieved by any other alternative is mınımal

The $\mathrm{B}^{*}$ probability based search algorithm has been implemented on the chess machine Hitech En route we have developed effective technıques for

- producing viable optimistic estimates to guide the search,

- producing cheap probability distribution estımates to measure goodness,

- dealing with independence of alternative moves, and

- dealing with the graph history interaction problem

The report describes the implementation, and the results of tests including games played against brute-force programs Test data indicate that $\mathrm{B}^{*}$ Hitech is better than any searcher that expands its whole tree based on selectivity Further, analysis of the data indicates that should additional power become available, the $\mathrm{B}^{*}$ technique will scale up considerably better than brute-force techniques "

1 This research was sponsored in part by the National Science Foundation under Grant Number IRI-9105202 The views and conclusions contained in this document are those of the authors and should not be interpreted as representıng the official policies, either expressed or implied, of the U S Government of NSF 